\title{
Effects of dietary ascorbic acid deficiency on Cryptobia salmositica infection and on vaccination against cryptobiosis in Oncorhynchus mykiss
}

\author{
S. $\mathrm{Li}^{1}{ }^{1}$ C. B. Cowey ${ }^{2}$, P. T. K. Woo ${ }^{1, *}$ \\ 'Department of Zoology, ${ }^{2}$ Department of Nutrition, University of Guelph, Guelph, Ontario, Canada N1G 2 W1
}

\begin{abstract}
Eight groups of Oncorhynchus mykiss were fed diets either lacking or supplemented with ascorbic acid (AA, $500 \mathrm{mg} \mathrm{kg}^{-1}$ diet) for $10 \mathrm{wk}$ prior to vaccination against cryptobiosis. The concentrations of AA in livers and kidneys of the fish correlated with those of the exogenous dietary AA. Fish were vaccinated intraperitoneally with 100000 attenuated Cryptobia salmositica per fish. They were challenged with 100000 virulent $C$. salmositica per fish 4 wk post-vaccination. Both vaccinated A. deficient and AA-supplemented fish were protected while unvaccinated controls had high parasitaemias and cryptobiosis (e.g. anaemia, abdominal distension with ascites) after being challenged with the pathogen. AA-deficlency did not significantly affect titres of complement fixing antibodies (CFAb) in vaccinated and vaccinated/challenged fish. However, detectable CFAb was delayed 1 wk in vaccinated and vaccinated/challenged fish fed the AA-deficient diet. Also the parasitaemias in infected and vaccinated/challenged AA-deficient fish were consistently lower than those in AA-supplemented fish. This indicates that A.A may have directly and indirectly promoted more rapid multiplication of the virulent parasite.
\end{abstract}

KEY WORDS: Cryptobia salmositica Ascorbic acid - Vaccination Cryptobiosis Protection

\section{INTRODUCTION}

Cryptobia salmositica is a pathogenic haemoflagellate found in Oncorhynchus spp. in freshwater streams in western North America (Woo 1987, 1994). The parasite causes cryptobiosis and mortality in naturally and experimentally infected rainbow trout Oncorhynchus mykiss (Wales \& Wolf 1955, Woo 1979). Some of the clinical signs are exophthalmia, abdominal distension with ascites, general oedema, splenomegaly, anaemia (Woo 1979), immunodepression (Jones et al. 1986) and anorexia (Li \& Woo 1991b, Thomas \& Woo 1992). The virulent $C$. salmositica was attenuated by in vitro culture and was used as a live vaccine against experimental cryptobiosis in rainbow trout (Woo \& Li 1990, Li \& Woo 1995).

The effects of dietary ascorbic acid (AA) on the immune response in fish are controversial. Dietary AA-

\footnotetext{
·Addressee for correspondence.E-mail: pwoo@uoguelph.ca
}

deficiency depressed cellular (Anderson et al. 1980) and humoral responses in channel catfish Ictalurus punctatus and rainbow trout to Vibrio anguillarum infection (Durve \& Lovell 1982, Navarre \& Halver 1989). A megadose of dietary AA in rainbow trout and channel catfish significantly enhanced humoral (Navarre \& Halver 1989) and cellular immune responses as well as complement haemolytic activity (Li \& Lovell 1985). However, Lall et al. (1989), Hardie et al. (1991) and Li et al. (1993) were unable to confirm the immunodepressive effects of dietary AA-deficiency either on Atlantic salmon Salmo salar infected with $V$. anguillarum and Aeromonas salmonicida or on channel catfish infected with Edwardsiella ictaluri.

The aims of the present study were to examine the effects of dietary AA on: (1) Cryptobia salmositica infection in Oncorhynchus mykiss; (2) protective immunity in rainbow trout vaccinated against cryptobiosis and the production of complement fixing antibodies. 
Table 2. Ascorbic acid (mean $\pm \mathrm{SE})(\mathrm{n}=4)$ stored in livers and kidneys of uninfected naive rainbow trout Oncorhynchus mykiss fed ascorbic acid deficient or ascorbic acid supplemented diets

\begin{tabular}{|c|c|c|c|}
\hline \multirow[t]{2}{*}{ Tissue samples } & \multirow{2}{*}{$\begin{array}{l}\text { Time on diets } \\
\qquad(w k)\end{array}$} & \multicolumn{2}{|c|}{ Ascorbic acid $\left(\mu \mathrm{g} \mathrm{g}^{-1}\right.$ tissue $)$} \\
\hline & & Ascorbic acid deficient diet & Ascorbic acid supplemented diet \\
\hline Liver & $\begin{array}{l}10 \\
14\end{array}$ & $\begin{aligned} 17.3 & \pm 13.8 \\
9.4 & \pm 0.9\end{aligned}$ & $\begin{array}{r}87.3 \pm 26.3^{\circ} \\
119.3 \pm 23.8^{\circ}\end{array}$ \\
\hline Kidney & $\begin{array}{l}10 \\
14\end{array}$ & $\begin{array}{l}17.1 \pm 11.8 \\
27.7 \pm 2.5\end{array}$ & $\begin{array}{r}79.8 \pm 36.0^{\circ} \\
165.6 \pm 14.2^{\circ}\end{array}$ \\
\hline
\end{tabular}

Table 3. Parasitaemias (mean $\pm \mathrm{SE})(\mathrm{n}=10)$ in vaccinated, vaccinated/challenged and infected rainbow trout Oncorhynchus mykiss fed ascorbic acid deficient ( $\mathrm{AA}-$ ) and supplemented $(\mathrm{AA}+)$ diets

\begin{tabular}{|c|c|c|c|c|c|c|}
\hline \multirow{3}{*}{$\begin{array}{l}\text { Time post-challenge } \\
\qquad(w k)\end{array}$} & \multicolumn{6}{|c|}{ Parasitaemias $\times 1000($ mean $\pm \mathrm{SE}) \mathrm{ml}^{-1}$ fish blood } \\
\hline & \multicolumn{2}{|c|}{ Vaccinated d } & \multicolumn{2}{|c|}{ Vaccinated/challenged ${ }^{b}$} & \multicolumn{2}{|c|}{ lnfected ${ }^{c}$} \\
\hline & AA- & $\mathrm{AAt}$ & AA- & $\mathrm{AA}+$ & $\mathrm{AA}-$ & $\mathrm{AA}+$ \\
\hline 3 & 0 & 0 & $75 \pm 28$ & $68 \pm 17$ & $244 \pm 96$ & $222 \pm 87$ \\
\hline 4 & $58 \pm 31$ & $58 \pm 30$ & $45 \pm 28$ & $68 \pm 17$ & $1633 \pm 96$ & $3585 \pm 87^{\circ}$ \\
\hline 5 & $143 \pm 45$ & $100 \pm 44$ & $75 \pm 39$ & $238 \pm 63^{\circ}$ & $3877 \pm 1000$ & $4650 \pm 677$ \\
\hline 6 & $123 \pm 60$ & $45 \pm 32$ & $118 \pm 43$ & $120 \pm 43$ & $1878 \pm 838$ & $3005 \pm 1453$ \\
\hline 7 & $88 \pm 56$ & $170 \pm 74$ & $88 \pm 33$ & $200 \pm 94$ & $1864 \pm 534$ & $2250 \pm 896$ \\
\hline 8 & $70 \pm 47$ & $110 \pm 60$ & $56 \pm 24$ & $100 \pm 52$ & $1958 \pm 485$ & $2075 \pm 949$ \\
\hline \multicolumn{7}{|c|}{ 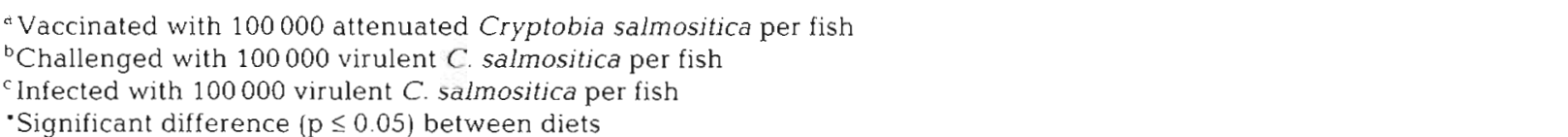 } \\
\hline
\end{tabular}

\section{Packed cell volumes}

Mean PCV of fish in the 4 subgroups fed AA-supplemented diet were not significantly different before challenge with the pathogen. PCV in infected controls decreased rapidly after infection and were significantly lower (indication of anaemia) than those in other subgroups from 5 wpi. As the disease progressed in infected controls, the anaemia became more severe. However, mean PCV were not significantly different between vaccinated, vaccinated/challenged or uninfected control subgroups (Table 4).

Similar results were also found in fish fed the AAdeficient diet (Table 4). The PCV between vaccinated and vaccinated/challenged subgroups were not significantly different before and after the challenge. Also, PCV in these 2 subgroups were not significantly different from those in uninfected naive controls lusing a linear regression test of mean PCV against wk). However, the mean PCV in infected controls decreased rapidly and were significantly lower after infection than those in other 3 subgroups (vaccinated, vaccinated/challenged and uninfected naive controls\}.
Mean PCV in AA-deficient vaccinated, vaccinated/ challenged and uninfected naive fish were significantly lower than those in AA-supplemented fish (Table 4). However, the mean PCV between infected controls were not significantly different between the diets.

\section{Complement fixing antibodies}

Detectable CFAb was found in the blood at $5 \mathrm{wpv}$ in 6 of 10 vaccinated fish and $1 \mathrm{wpc}$ in 5 of 10 vaccinated/challenged fish fed AA-supplemented diet. In subsequent weeks, CFAb was detected in all vaccinated and vaccinated/challenged fish. Mean CFAb titres increased rapidly in both subgroups; however, the titres in vaccinated/challenged fish were consistently higher than those in vaccinated fish. The detectable CFAb was delayed $1 \mathrm{wk}$ in fish given the AA-deficient diet. It was first found at $6 \mathrm{wpv}$ in vaccinated fish and at $2 \mathrm{wpc}$ in vaccinated/challenged fish. Mean titres of CFAb in these fish also increased rapidly; there were no significant differences either between vaccinated and vaccinated/challenged fish or 
Table 4. Packed cell volumes (mean $\pm \mathrm{SE}$ ) in vaccinated, vaccinated/challenged, infected and uninfected rainbow trout Oncorhynchus mykiss fed ascorbic acid deficient (AA-) and ascorbic acid supplemented (AA+) diets

\begin{tabular}{|c|c|c|c|c|c|c|c|c|}
\hline \multirow[t]{2}{*}{$\begin{array}{l}\text { Time post- } \\
\text { challenge ( } w \mathrm{k})\end{array}$} & \multicolumn{2}{|c|}{$\begin{array}{l}\text { Vaccinated } \\
\qquad(\mathrm{n}=10)\end{array}$} & \multicolumn{2}{|c|}{$\begin{array}{l}\text { Packed cell } \\
\text { Vaccinated/challenged } \\
(n=10)\end{array}$} & \multicolumn{2}{|c|}{$\begin{array}{l}(\%) \text { (mean } \pm S E) \\
\text { Infected } \\
(\mathrm{n}=10)\end{array}$} & \multicolumn{2}{|c|}{$\begin{array}{l}\text { Uninfected } \\
\qquad(\mathrm{n}=8)\end{array}$} \\
\hline & $\mathrm{AA}-$ & AAt & $\mathrm{AA}-$ & $\mathrm{AA}+$ & $A A-$ & $\mathrm{AAt}$ & $A A-$ & $\mathrm{AA}+$ \\
\hline 0 & $21.3 \pm 1.3$ & $29.2 \pm 2.1$ & $23.7 \pm 2.3$ & $28.5 \pm 1.5$ & $32.0 \pm 1.1$ & $33.9 \pm 1.7$ & $29.3 \pm 1.6$ & $32.4 \pm 1.6$ \\
\hline 3 & $24.8 \pm 1.3$ & $30.9 \pm 0.8$ & $22.5 \pm 1.3$ & $30.2 \pm 1.6$ & $27.0 \pm 1.9$ & $29.9 \pm 1.6$ & $32.8 \pm 0.8$ & $31.8 \pm 1.7$ \\
\hline 4 & $23.2 \pm 1.3$ & $29.0 \pm 1.3^{\mathrm{a}}$ & $23.4 \pm 1.6$ & $29.4 \pm 1.2^{\mathrm{d}}$ & $21.0 \pm 1.5^{b}$ & $24.7 \pm 2.0^{b}$ & $28.4 \pm 0.8$ & $32.9 \pm 1.5$ \\
\hline 5 & $21.8 \pm 1.2$ & $29.9 \pm 1.3^{a}$ & $23.6 \pm 1.9$ & $28.8 \pm 1.1^{\circ}$ & $18.2 \pm 1.0^{h}$ & $17.1 \pm 1.3^{\mathrm{b}}$ & $27.6 \pm 1.5$ & $32.1 \pm 1.4$ \\
\hline 6 & $21.2 \pm 1.4$ & $32.1 \pm 1.4^{\mathrm{a}}$ & $21.0 \pm 1.9$ & $29.7 \pm 1.6^{\mathrm{a}}$ & $17.4 \pm 1.4^{b}$ & $18.0 \pm 2.3^{b}$ & $28.6 \pm 2.3$ & $35.0 \pm 1.6^{b}$ \\
\hline 7 & $21.8 \pm 1.1$ & $28.9 \pm 0.7^{\mathrm{d}}$ & $23.3 \pm 2.0$ & $30.4 \pm 1.0^{n}$ & $16.8 \pm 1.0^{\prime \prime}$ & $17.7 \pm 2.6^{b}$ & $29.3 \pm 1.8$ & $32.2 \pm 1.2$ \\
\hline 8 & $21.4 \pm 1.0$ & $28.0 \pm 1.4^{\mathrm{d}}$ & $22.6 \pm 2.1$ & $29.4 \pm 1.1^{\circ}$ & $15.2 \pm 1.6^{b}$ & $18.6 \pm 3.0^{b}$ & $26.0 \pm 1.2$ & $32.9 \pm 1.3^{b}$ \\
\hline
\end{tabular}

Table 5. Titres (mean $\pm \mathrm{SE})(\mathrm{n}=10)$ of complement fixing antibodies in vaccinated, vaccinated/challenged, and infected controls fed ascorbic acid supplemented (AA+) or deficient (AA-) diets

\begin{tabular}{|c|c|c|c|c|c|c|}
\hline \multirow{3}{*}{$\begin{array}{l}\text { Time post- } \\
\text { challenge (wk) }\end{array}$} & \multicolumn{6}{|c|}{ Titres $\left(\log _{2}\right)$ of complement fixing antibodies (mean $\pm \mathrm{SE}$ ) } \\
\hline & \multicolumn{2}{|c|}{ Vaccinated $^{\alpha}$} & \multicolumn{2}{|c|}{ Vaccinated/challenged ${ }^{b}$} & \multicolumn{2}{|c|}{ Infected controls ${ }^{c}$} \\
\hline & $\mathrm{AA}+$ & AA- & $\mathrm{AA}+$ & AA- & $\mathrm{AA}+$ & AA- \\
\hline 1 & $0.7 \pm 0.3$ & 0 & $0.7 \pm 0.3$ & 0 & 0 & 0 \\
\hline 2 & $2.2 \pm 0.3$ & $1.9 \pm 0.2$ & $2.8 \pm 0.3$ & $2.7 \pm 0.2$ & 0 & 0 \\
\hline 3 & $2.9 \pm 0.2$ & $3.0 \pm 0.2$ & $3.0 \pm 0.2$ & $3.3 \pm 0.3$ & 0 & 0 \\
\hline 4 & $3.8 \pm 0.4$ & $3.6 \pm 0.3$ & $4.4 \pm 0.3$ & $4.2 \pm 0.3$ & 0 & 0 \\
\hline 5 & $3.0 \pm 0.2$ & $3.5 \pm 0.2$ & $3.6 \pm 0.3$ & $3.1 \pm 0.3$ & 0 & 0 \\
\hline 6 & $3.5 \pm 0.5$ & $4.1 \pm 0.4$ & $3.8 \pm 0.5$ & $3.9 \pm 0.4$ & 0 & 0 \\
\hline 7 & $3.0 \pm 0.6$ & $3.7 \pm 0.3$ & $4.0 \pm 0.3$ & $4.2 \pm 0.3$ & $0.9 \pm 0.1$ & $0.6 \pm 0.2$ \\
\hline 8 & $2.9 \pm 0.4$ & $2.9 \pm 0.3$ & $3.4 \pm 0.3$ & $3.4 \pm 0.4$ & $2.1 \pm 0.2$ & $2.0 \pm 0.3$ \\
\hline $\begin{array}{l}\text { 'Vaccinated wit } \\
\text { bVaccinated fish } \\
\text { 'Infected with } 1\end{array}$ & $\begin{array}{l}0 \text { attenua } \\
\text { hallengec } \\
\text { irulent } C\end{array}$ & $\begin{array}{l}\text { Cryptobic } \\
\text { th } 100000 \\
\text { Imositica p }\end{array}$ & $\begin{array}{l}\text { per fish } \\
\text { salmositica }\end{array}$ & fish & & \\
\hline
\end{tabular}

between diets from 2 wpc (or 6 wpv) (Table 5). The CFAb in infected controls was detected in 5 of $10 \mathrm{AA}$ deficient fish and 6 of $10 \mathrm{AA}$-supplemented fish from 7 wpi. CFAb was found in all infected fish in subsequent weeks. No detectable CFAb was found in uninfected naive controls.

\section{DISCUSSION}

Ascorbic acid is an essential dietary component for normal physiological functions and growth of fish (Tucker \& Halver 1986). Rainbow trout are particularly reliant upon exogenous dietary AA because they lack the L-gulonolactone oxidase needed for AA synthesis from glucose (Dabrowski 1990). Therefore, the dietary AA intake influences AA contents in the liver and kidney (Navarre \& Halver 1989, Hardie et al. 1991, Al-
Amoudi et al. 1992, present study). The high standard error in some AA measurements was due to the relatively small sample size.

Cryptobia salmositica requires protein and glucose for in vivo and in vitro multiplication (Li \& Woo 1991a, b). In the present study, the parasitaemias in infected or vaccinated/challenged fish with virulent parasites were consistently and significantly higher (at 4 wpi or $5 \mathrm{wpc}$ ) in AA-supplemented fish than in AA-deficient fish. This may indicate that the higher ascorbic acid content in tissues may have directly or indirectly promoted more rapid multiplication of the virulent parasite.

The present study confirmed that the live Cryptobia salmositica vaccine protected trout against cryptobiosis (Woo \& Li 1990, Li \& Woo 1995). In an earlier study, Wahli et al. (1986) showed that ascorbic acid increased immune response in rainbow trout infected 
with Ichthyophthirius multifiliis and this resulted in reduced mortality. Results of the present study indicated that the dietary AA did not affect protection by the live vaccine in rainbow trout. Similar results were reported in Atlantic salmon against Vibrio anguillarum (Lall et al. 1989). The production of protective CFAb (present study) and agglutinating antibodies (Lall et al. 1989, Hardie et al. 1991) were independent of dietary AA. However, Li \& Lovell (1985) and Navarre \& Halver (1989) found that production of agglutinating antibodies was depressed under conditions of AA deficiency. Since agglutinating antibodies in fish may not be protective (Salati 1988, Landolt 1989), it is important to measure the effects of $A A$ on the production of protective antibodies, such as CFAb which causes lysis of parasites under in vitro conditions ( $\mathrm{Li} \&$ Woo 1995, present study). The present study demonstrated that the production of protective CFAb was not significantly affected by the dietary AA.

Vaccination with the live vaccine establishes an immunological memory, and vaccinated fish respond rapidly against the pathogen (Li \& Woo 1995). The dietary AA deficiency did not significantly affect the establishment of an immunological memory in vaccinated trout. Production of protective CFAb in vaccinated fish was more rapid, and the titres were significantly higher, than in those of unvaccinated infected controls for both diets (present study). Although the detectable CFAb was delayed for $1 \mathrm{wk}$ in fish given the AA-deficient diet, the mean CFAb production in fish given either diet was not significantly different from $<2$ wpc (or 6 wpv) onward. All AA-supplemented and AA-deficient fish were protected from cryptobiosis by the live vaccine. In addition, there was no cryptobiosis in fish inoculated with the vaccine compared with unvaccinated infected fish, which had high parasitaemias, were anaemic and had abdominal distension with ascites

Anaemia, one of the clinical signs of AA-deficiency, was also found in uninfected AA-deficient fish in the present study. Internal haemorrhage (Halver et al. 1969) and haemolysis (Chazan \& Mistilis 1963, Goldberg 1963) might have contributed to andemia in AA-deficient fish. However, anaemia in infected controls was caused by both the parasite (Thomas \& Woo 1989a, b) and A.A-deficiency, and it was more severe than in the uninfected AA-deficient fish.

Acknowledgements. This study was supported by grants from the Department of Fisheries and Ocean (Canada) and the Natural Sciences and Engineering Research Council (Canada) to P.T.K.W

\section{LITERATURE CITED}

Al-Amoudi MM, El-Nakkadi AMN, El-Nouman BM (1992) Evaluation of optımum dietary requirement of vitamin $C$ for the growth of Oreochromis spilurus fingerlings in water from the Red Sea. Aquaculture 105:165-173

Anderson R, Oosthuizen R, Maritz B, Theron A, Van Rensburg AJ (1980) The effects of increasing weekly doses of ascorbic acid on certain cellular and humoral immune functions in normal volunteers. Am J clin Nutr 33:71-76

Archer RK (1965) Haematological techniques for use on animals. Blackwell Scientific Publications, Oxford

Chazan JA, Mistilis SP (1963) The pathophysiology of scurvy. Am J Med 34:350-358

Dabrowski K (1990) Gulonolactone oxidase is missing in teleost fish. The direct spectrophotometric assay. Biol Chem Hoppe-Seyler 371:207-214

Durve VS, Lovell RT (1982) Vitamin C and disease resistance in channel catfish (Ictalurus punctatus). Can J Fish Aquat Sci 39:948-951

Goldberg A (1963) The anaemia of scurvy. Q J Med 32:51-64

Halver JE, Ashley LM, Smith RR (1969) Ascorbic acid requirements of coho salmon and rainbow trout. Trans Am. Fish Soc 98:762-771

Hardie LJ, Fletcher TC. Secombes CJ (1991) The effect of dietary vitamin $\mathrm{C}$ on the immune response of the Atlantic salmon (Salmo salar L.). Aquaculture 95:201-214

Jones SRM, Woo PTK, Stevenson RMW (1986) Immunosuppression in rainbow trout, Salmo gairdneri Richardson caused by the haemoflagellate Cryptobia salmositica Katz 1951. J Fish Dis 9:431-438

Lall SP, Olivier G, Weerakoon DEM, Hines JA (1989) The effect of vitamin $C$ deficiency and excess on immune response in Atlantic salmon (Salmo salar L.). In: Takeda M, Watanabe T (eds) The current status of fish nutrition in aquaculture Japan Translation Center, Ltd, Tokyo, p 427-447

Landolt ML (1989) The relationship between diet and the immune response of fish. Aquaculture 79:193-206

Li MH, Johnson MR, Robinson EH (1993) Elevated dietary vitamin $\mathrm{C}$ concentrations did not improve resistance of channel catfish, Ictalurus punctatus, against Edwardsiella ictaluri infection. Aquaculture 117:303-312

Li S, Woo PTK (1991a) In vitro effects of fetal bovine serum and glucose on multiplication of Cryptobia salmositica. J Parasitol 77:151-155

Li S, Woo PTK (1991b) Anorexia reduces the severity of cryptobiosis in Oncorhynchus mykiss. J Parasitol 77:467-471

Li S, Woo PTK (1995) Efficacy of a live Cryptobia salmositica vaccine, and the mechanism of protection in vaccinated Oncorhynchus mykiss against cryptobiosis. Vet Immunol Immunopathol (in press)

Li Y, Lovell RT (1985) Elevated levels of dietary ascorbic acid increase immune responses in channel catfish. J Nutr 115: $123-131$

Navarre O, Halver JE (1989) Disease resistance and humoral antibody production in rainbow trout fed high levels of vitamin C. Aquaculture 79:207-221

Sakai DK (1981) Heat inactivation of complements and immune haemolysis reactions in rainbow trout, Masu salmon, Coho salmon, goldfish and tilapia. Bull Jap Soc scient Fish 47:565-571

Salati $F$ (1988) Vaccination against Edwardsiella tarda. In: Ellis AE (ed) Fish vaccination. Academic Press, London, p $135-151$

Thomas PT, Woo PTK (1989a) An in vitro study on the haemolytic components from Cryptobia salmositica (Sarcomastigophora: Kinetoplastida). J Fish Dis 12:389-393 
Thomas PT, Woo PTK (1989b) Complement activity in Salmo gairdneri Richardson infected with Cryptobia salmositica (Sarcomastigophora: Kinetoplastida) and its relationship to the anaemua in cryptobiosis. J Fish Dis $12: 395-397$

Thomas PT, Woo PTK (1992) Anorexia in Oncorhynchus mykiss infected with Cryptobia salmositica (Sarcomastigophora: Kinetoplastida): its onset and contribution to the immunodepression. J Fish Dis 15:443-447

Tucker BW, Halver JE (1986) Vitamin C metabolism in rainbow trout. Comp Pathol Bull 18:1 \& 6

Wales JH, Wolf K (1955) Three protozoan diseases of trout in California. Calif Fish Game 41:183-187

Walhi T, Meies W, Pfister K (1986) Ascorbic acid induced immune-mediated decrease in mortality in Ichthyophthirius multifiliis infected rainbow trout. Acta Trop 43: $387-289$

Wang $X$, Laio $M$, Hung T, Seib PA (1988) Liquid chromatographic determination of $\mathrm{L}$-ascorbate 2-polyphosphate in

Responsible Subject Editor: W. Körting, Hannover, Germany fish feeds by enzymatic release of L-ascorbate. J Ass off analyt Chem 71:1158-1161

Woo PTK (1969) The hematocrit centrifuge for the detection of trypanosomes. Can J Zool 47:921-923

Woo PTK (1979) Trypanoplasma salmositica: experimental infection in rainbow trout Salmo gairdneri. Expl Parasitol $47: 36-48$

Woo PTK (1987) Cryptobia and cryptobiosis in fishes. In: Baker JR, Muller R (eds) Advances in parasitology, Vol 26. Academic Press, London, p 199-237

Woo PTK (1994) Flagellate parasites of fish. In: Kreier JP (ed) Parasitic Protozoa, Vol 8. Academic Press, New York, p 1-80

Woo PTK, Li S (1990) In vitro attenuation of Cryptobia salmositica and its use as a live vaccine against cryptobiosis in Oncorhynchus mykiss. J Parasitol 76:752-755

Woo PTK, Wehnert SD (1983) Direct transmission of a haemoflagellate, Cryptobia salmositica (Kinetoplastida: Bodonina) between rainbow trout under laboratory conditions. J Protozool 30:334-337

Manuscript first received: February 23, 1995

Revised version accepted: July 19, 1995 